\title{
BALANCED SCORECARD EM UMA CLÍNICA DE CIRURGIA PLÁSTICA: UMA PROPOSTA DE FERRAMENTA PARA GESTÃO ESTRATÉGICA ${ }^{1}$
}

\section{BALANCED SCORECARD IN A PLASTIC SURGERY CLINIC: A STRATEGIC MANAGEMENT TOOL PROPOSAL}

\section{BALANCED SCORECARD EN UNA CLÍNICA DE CIRUGÍA PLÁSTICA: INSTRUMENTO PROPUESTO PARA LA GESTIÓN ESTRATÉGICA}

\author{
Gustavo Vanzo Odebrecht \\ Faculdades Integradas Associação de Ensino de Santa \\ Catarina - ASSESC \\ gu_odebrecht@hotmail.com
}

Jonas Duarte da Silva

Estaleiro Schaefer Yachts

jonasduarte-s@uol.com.br

\author{
Pollyanna Gerola Giarola \\ JBS- Friboi \\ polly.gerola@gmail.com
}

Cristina Martins

Universidade Federal de Santa Catarina crismartins2611@gmail.com

Carlos Rogério Montenegro de Lima
Universidade Federal de Santa Catarina
carlos.montenegro@ unisul.br

\section{RESUMO}

Na gestão estratégica competitiva, o grande desafio é alinhar o planejamento estratégico com o estabelecimento de medidas, metas e iniciativas para a realização dos objetivos empresariais. O Balanced Scorecard (BSC) é uma ferramenta que proporciona este alinhamento e fornece informações para o monitoramento do negócio e tomadas de decisão consistentes e ágeis. Considerando o exposto, este artigo tem como objetivo propor uma ferramenta de gestão estratégica para uma Clínica de Cirurgia Plástica, por meio da estruturação de um BSC, contribuindo para que a organização possa, além de monitorar resultados financeiros, acompanhar o progresso na construção da aquisição de ativos intangíveis necessários para o crescimento futuro. A abordagem da pesquisa é qualitativa e quanto aos objetivos se considera exploratória. As estratégias de pesquisa utilizadas foram bibliográfica, documental e estudo de caso. Os resultados da pesquisa indicam que: (i) as estratégias da organização estão traduzidas em iniciativas e ações; (ii) os objetivos estratégicos foram transformados em metas operacionais; e (iii) o mapeamento estratégico da clínica gerou uma visão holística e alinhada das estratégias.

Palavras-Chaves: Balanced Scorecard. Mapa estratégico. Indicadores de desempenho.

\begin{abstract}
At the competitive strategic management, the challenge is to align strategic planning with the establishment of measures, targets and initiatives to achieve the business objectives. The Balanced Scorecard (BSC) is a tool that provides this alignment and provides information for monitoring of business and consistent and agile decision making. Considering the above, this paper aims to propose a strategic management tool for a Clinic of Plastic Surgery, through the structuring of a BSC, contributing to the organization to monitor financial performance, and monitor progress in the construction of the acquisition of intangible assets needed for future growth. The research approach is qualitative and it is considered exploratory in nature. The research strategies used were bibliographic, documental, and case study. The survey results show that: (i) the organization's strategies and initiatives are translated into actions; (ii) the strategic objectives were transformed into operational goals; and (iii) the strategic mapping of the clinic generated a holistic and aligned vision of the strategies.
\end{abstract}

\footnotetext{
${ }^{1}$ Submetido em 25 de Outubro 2012. Aceito em 12 de junho de 2013. O artigo foi avaliado segundo o processo de duplo anonimato além de ser avaliado pelo editor. Editores responsáveis: Márcio Augusto Gonçalves e Lucas Maia dos Santos. Reprodução parcial ou total e trabalhos derivativos permitidos com a citação apropriada da fonte.
} 
Key Words: Balanced Scorecard. Strategic maps. Performance indicators.

\section{RESUMEN}

En la gestión estratégica competitiva, el reto es alinear la planificación estratégica con el establecimiento de medidas, metas e iniciativas para alcanzar los objetivos de negocio. El Balanced Scorecard (BSC) es una herramienta que proporciona esta alineación y proporciona información para el seguimiento de negocios y toma de decisiones coherente y ágil. Teniendo en cuenta lo anterior, el presente trabajo tiene como objetivo proponer una herramienta de gestión estratégica de una clínica de cirugía plástica , a través de la estructuración de un BSC, contribuyendo a la organización puede, y monitorear el desempeño financiero, seguimiento de los progresos en la creación de adquisición activos intangibles necesarios para el crecimiento futuro. El enfoque de la investigación es cualitativo y sobre los objetivos considerados exploratoria. Las estrategias de búsqueda utilizadas fueron estudio bibliográfico, documental y caso. Los resultados de la encuesta indican que: (i) las estrategias e iniciativas de la organización se traducen en acciones, (ii) los objetivos estratégicos se transformaron en objetivos operativos , y (iii) la asignación estratégica de clínica generan una visión holística y alineadas las estrategias .

Palabras clave: Balanced Scorecard. Mapa Estratégico. Los indicadores de desempeño.

\section{INTRODUÇÃO}

Em meio a um ambiente em constantes mudanças - alterações de paradigmas, globalização -, novas tendências preocupam os empresários, tais como: planejamento estratégico, vantagem competitiva, sustentabilidade e ameaças. Assim, as empresas que desejam obter fortalecimento perante aos concorrentes devem estar em estreita sintonia com o mundo dos negócios.

Neste contexto, executivos e colaboradores de diversas organizações permanecem em constante vigilância para descobrir qual é a nova boa ideia ou qual a nova tendência sobre gestão empresarial do momento para aplicarem em suas organizações, a fim de obterem melhor desempenho e vantagem competitiva nos negócios. Mas, nem sempre essas ideias dão certo, gerando a frustração, por motivos que vão da falta de comprometimento da alta cúpula, até pelo não cumprimento das expectativas geradas por estas próprias ideias. Contudo, ressalta-se que o fator decisivo na maioria das vezes não se encontra na escolha da estratégia, mas sim na capacidade de sua execução, ou seja, no modo como a empresa atende seus clientes, na presteza e na qualificação dos funcionários, na qualidade dos serviços/produtos, no controle de custos, na política de preços, e até mesmo em algum processo de tomada de decisão (KAPLAN; NORTON, 1997).

Outro ponto relevante é a tendência histórica dos sistemas de avaliação de desempenho organizacional ficarem reduzidos à dimensão financeira com indicadores oriundos da contabilidade, pois a preocupação básica dos administradores até a década de 1960 era melhorar a produtividade para aumentar os lucros da organização (COELHO, 2008, p. 3; LIMA; SOARES; LIMA, 2011).

No entanto, tomar como base apenas o sistema de contabilidade tradicional, onde as tomadas de decisões se concretizavam sobre aspectos financeiros passados já não é o suficiente em meio ao novo ambiente competitivo. Há a necessidade de considerar aspectos que ultrapassem a dimensão financeira e neste sentido, o Balanced Scorecard (BSC) é tido como um modelo de gestão estratégica que possibilita o controle e a disseminação participativa da estratégia, envolvendo e integrando toda a organização.

Antes visto apenas como um sistema de medição do desempenho, o BSC agora se torna um sistema de gerenciamento que alinha e focaliza a organização, além de introduzir e aperfeiçoar sua estratégia. Desta forma, considerando a necessidade de reformulação de estratégias das empresas baseadas na antiga gestão organizacional - centralizadora e baseada apenas em aspectos financeiros - para a nova gestão - flexibilizada e com fatores intangíveis - 
é que emerge a pergunta que norteará esta pesquisa: como pode ser desenvolvido um sistema de gestão para uma clínica de cirurgias plásticas por meio do Balanced Scorecard?

Para responder o problema levantado, este artigo objetiva propor uma ferramenta de gestão estratégica organizacional para a Clínica de Cirurgia Plástica Jane de Florianópolis, por meio da estruturação de um Balanced Scorecard - o que contribui para que a organização possa, além de monitorar resultados financeiros, acompanhar o progresso na construção da aquisição de ativos intangíveis necessários para o crescimento futuro.

Para cumprir o objetivo geral, foram estabelecidos alguns objetivos específicos, a saber: (i) identificar objetivos estratégicos da empresa; (ii) realizar a análise SWOT Strenghts (Forças), Weakness (Fraquezas), Opportunities (Oportunidades) e Threats (Ameaças) (iii) elaborar o mapa estratégico na metodologia do BSC; (iv) propor indicadores, metas e iniciativas para os objetivos organizacionais dentro das perspectivas do BSC.

$\mathrm{O}$ presente estudo está estruturado em quatro seções além desta. Na segunda seção apresenta-se o referencial teórico; a terceira seção descreve os procedimentos metodológicos; na quarta seção é apresentada a proposta de implementação do Balanced Scorecard; e, por fim, na seção cinco são apresentadas as considerações finais.

\section{REFERENCIAL TEÓRICO}

Os fundamentos teóricos que norteiam a presente pesquisa envolvem o Balanced Scorecard e o Planejamento Estratégico.

\subsection{BALANCED SCORECARD}

Com a identificação dos princípios de uma organização guiada pela estratégia, o BSC é uma ferramenta estratégica que auxilia na discriminação em nível gerencial até o nível operacional (KAPLAN; NORTON, 1997).

O significado do BSC tem sua funcionalidade como uma metodologia de medição e gestão de desempenho. Na seara administrativa o BSC representa um sistema de gestão estratégico que se fundamenta em indicadores de desempenho (SERRA; TORRES, M. C.; TORRES, A., 2003). Ele ainda pode ser traduzido como um cartão de marcação balanceado ou indicadores balanceados de desempenho (LUZ, 2010), em que se conhece a empresa através de números.

Segundo Herrero Filho (2005), o BSC é uma ferramenta ou um modelo que tem sua ênfase no controle de metas estratégicas como se pode visualizar na figura 1.

Figura 1 - os Princípios da Organização Orientada para a Estratégia

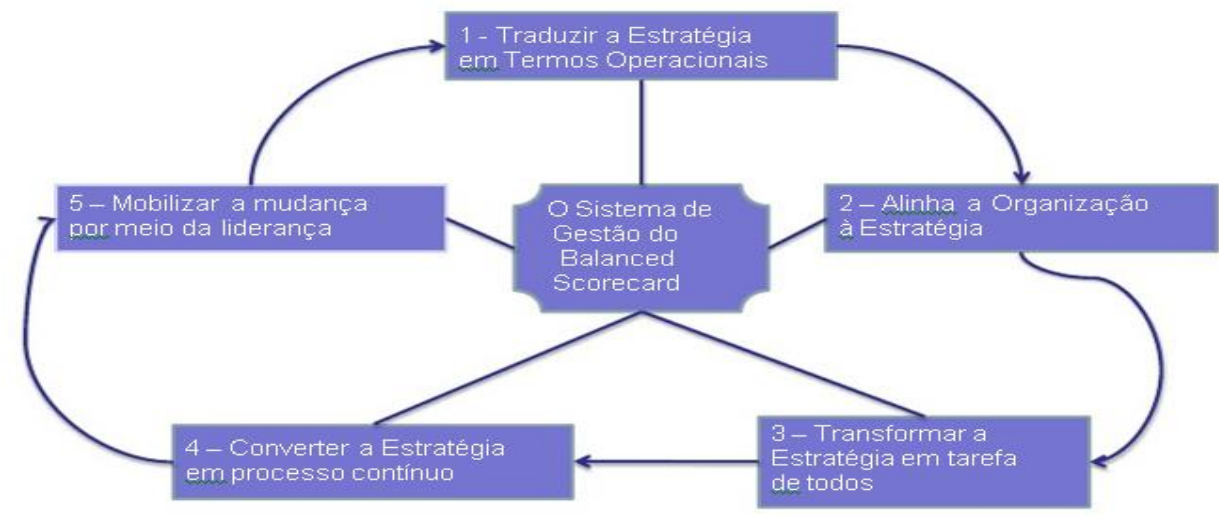


Revista de Administração Hospitalar, v.10, n.2, pp. 13-29, maio/agosto, 2013/ Gustavo Vanzo Odebrecht; Pollyanna Gerola Giarola; Jonas Duarte da Silva; Cristina Martins; Carlos Rogério Montenegro de Lima

Fonte: adaptado de Herrero Filho (2005, p. 33).

Este sistema de gestão admite que a organização tenha uma visão estratégica e que se insira o objetivo estratégico no dia a dia de todos os colaboradores.

\subsubsection{Histórico do Balanced Scorecard}

Considerando a nova configuração da competição e a mudança de paradigmas percebe-se que os métodos até então utilizados pelas empresas para suas análises e certificações têm se tornando obsoletos (KAPLAN; NORTON, 2004). Corroborando com esta afirmação, Coelho (2008, p. 3) coloca que até a década de 1960, a preocupação básica dos administradores era apenas melhorar a produtividade para aumentar os lucros da organização. Contudo, fatores como mudanças tecnológicas, a globalização, a diversidade cultural onde se mesclam nacionalidades e culturas, e a capitalização desencadearam aspectos capazes de transformar o ambiente externo e o comportamento humano, gerando como consequência, intensas mudanças organizacionais.

De acordo com Herrero Filho (2005), em uma sociedade onde os clientes exigem cada vez mais de produtos/serviços, marcada por meios de comunicação avançada (internet) e redes de comunicação entre pessoas e empresas (networking), cuidar apenas da situação financeira da empresa não é o suficiente. As empresas atuais buscam obter vantagem competitiva, destacando-se de seus concorrentes através da diferenciação da gestão estratégica. Neste contexto, cabe ressaltar ainda a importância de mensuração da qualidade estratégica das corporações, não somente a curto prazo, mas também a longo prazo.

$\mathrm{Na}$ era industrial, as notas financeiras possuíam uma relevância fundamental para as organizações, já que não existia a necessidade de investimentos de longo prazo para capacidade e relacionamento com clientes, pois os métodos para avaliação do desempenho industrial em geral apoiavam-se em indicadores contábeis e financeiros que, segundo Kaplan e Norton (1997, p. 7), estavam se tornando ultrapassados, prejudicando a capacidade das empresas de criar valor econômico para o futuro. Niven $(2005$, p. 16) ainda complementa que se pode classificar as medidas financeiras como indicadores de resultado, onde estes são o resultado das ações anteriormente praticadas. Neste contexto, o BSC completa estes indicadores com os orientadores do desempenho econômico futuro, ou indicadores de tendência.

Frente ao exposto, entende-se que a partir do desenvolvimento de organizações complexas foram exigidos métodos estruturados para solução de problemas. Estas organizações complexas passaram a exigir muito mais do empreendedor, que deve assumir uma nova postura embasada em qualidades: interpessoal (boa postura de convivência), intrapessoal (capacidade de exercer autocrítica) e habilidade de saber ler sinais externos que interferem na organização.

No livro "A Estratégia do Oceano Azul”, Kim (2005) diz que atualmente existem dois oceanos no mundo dos negócios - o oceano azul e o oceano vermelho. O oceano vermelho baseia-se na concorrência, onde existe uma competitividade acirrada por organizações do mesmo setor. Já o oceano azul é onde "navegam" as organizações, em outras palavras, onde não existe concorrência direta e as organizações já criaram um diferencial que nenhuma empresa consegue competir.

Objetivando a ideia da criação de um sistema adaptado às realidades dos dias atuais, Robert Kaplan e David Norton (1997) criaram em meados da década de noventa o Balanced Scorecard, partindo da premissa de que somente um sistema de medidas financeiras era insuficiente, tendo em vista que estes são indicadores de desempenho que informam 
resultados de ações passadas. O BSC surgiu então, como uma ferramenta que traduz a visão de negócio num conjunto abrangente de medidas que servem de base para um sistema de medição e gestão estratégica fundamentando-se em indicadores que proporcionam uma visão futura de negócio de acordo com cada uma de suas perspectivas (Kaplan; Norton, 2004, p. 7; Niven, 2005). Adicionalmente Niven (2005, p. 16) coloca que o BSC cumpre três finalidades: é um sistema de medição, um sistema de gerenciamento estratégico e uma ferramenta de comunicação.

Os estudos iniciais para o desenvolvimento da ferramenta BSC aplicadas ao comportamento de doze empresas - com o intuito de criar um sistema de controle gerencial adaptado a realidade dos dias atuais (NIVEN, 2005) - gerou grandes modificações no conceito de estratégia, bem como constatou a necessidade de aproximá-la das atuações nas organizações, identificando que os novos sistemas deveriam também se importar com a utilização de critérios não-financeiros, pois não consentiam esta prioridade até o momento. Surgindo assim, a partir da necessidade de captar toda a complexidade da performance da organização, uma ferramenta que pudesse interagir na relação entre a estratégia e medidas não financeiras, determinada Balanced Scorecard (KAPLAN; NORTON, 1997; BASSO; PACE, 2003), o qual tem sido ampla e crescentemente utilizado em empresas e organizações.

\subsubsection{Estrutura do Balanced Scorecard}

São conhecidas duas expressões para os objetivos do BSC: quadrantes ou perspectivas. A fim de normalizar a abordagem, este artigo adota a expressão perspectiva. Sua estrutura basicamente traduz e analisa a estratégia da organização em quatro perspectivas: finanças, clientes, processos internos, aprendizado e crescimento. Cada uma possui seus próprios objetivos, metas, medidas e iniciativas, operacionalizando a estratégia e avaliando a realização das perspectivas (NIVEN, 2005).

Neste sentido, essas quatro perspectivas subsidiaram a construção da ferramenta por Kaplan e Norton (1997, p. 2), os quais asseveram que o BSC permite além do monitoramento do desempenho financeiro das empresas, o acompanhamento paralelo do progresso na construção de capacidades e na aquisição dos ativos intangíveis imprescindíveis para o crescimento futuro. Os mesmos autores dispõem estas quatro perspectivas conforme figura 2.

Figura 2 - perspectivas do Balanced Scorecard 


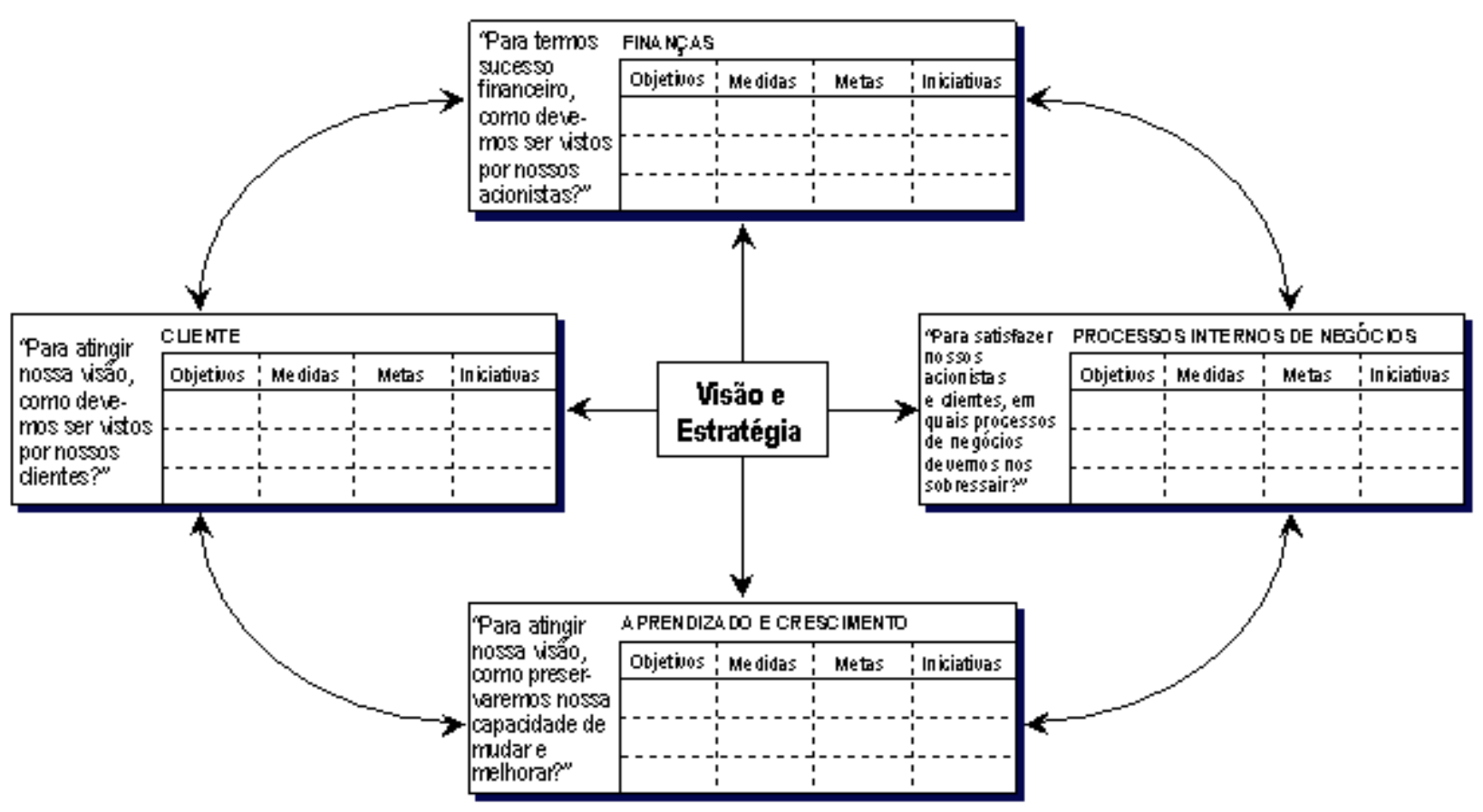

Fonte: adaptado de Kaplan; Norton, (1997).

Nos moldes de Herrero Filho (2005), as quatro perspectivas do Balanced Scorecard são dispostas conforme demonstra a figura 3.

Figura 3 - Perspectivas do Balanced Scorecard

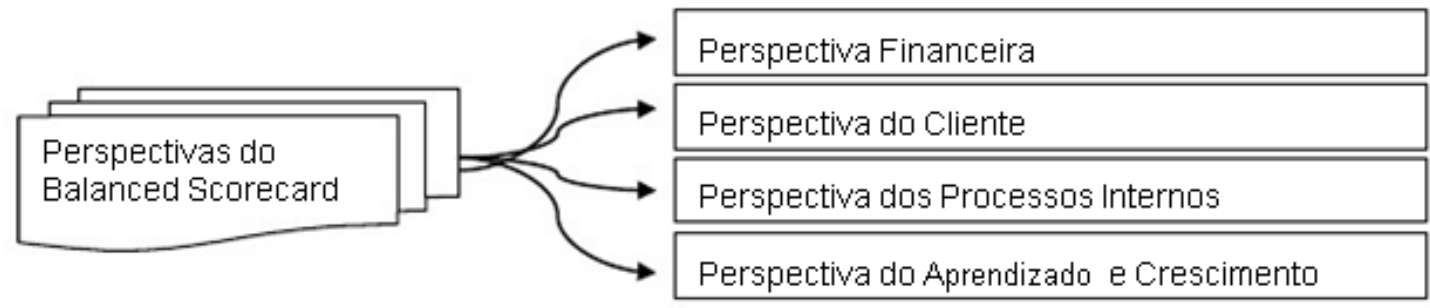

Fonte: Herrero Filho (2005, p. 39).

Contudo, independente da disposição, cabe explanar para melhor compreensão o que cada uma das quatro perspectivas representa.

\section{Da perspectiva de finanças}

Conceituando a ideia da perspectiva de finanças, Kaplan e Norton (1997, p. 49) colocam que os objetivos financeiros proporcionam foco para os objetivos e medidas das outras perspectivas desta ferramenta.

Herrero Filho (2005, p. 30) complementa que esta perspectiva demonstra se a execução da estratégia está alinhada e contribuindo para a melhoria dos resultados financeiros, em especial o lucro líquido, o retorno sobre o investimento, a criação de valor econômico e a geração de caixa. Em outras palavras, o BSC permite tornar os objetivos financeiros explícitos, ajustando-se às unidades de negócios nas diferentes fases do seu ciclo de vida e crescimento (Kaplan e Norton, 1997, p. 64). Nesta perspectiva, emerge a seguinte indagação: "para sermos bem-sucedidos financeiramente, como deveríamos ser vistos pelos nossos acionistas?” (KAPLAN; NORTON, 1997, p. 10). 
Revista de Administração Hospitalar, v.10, n.2, pp. 13-29, maio/agosto, 2013/ Gustavo Vanzo Odebrecht; Pollyanna Gerola Giarola; Jonas Duarte da Silva; Cristina Martins; Carlos Rogério Montenegro de Lima

\section{Da perspectiva dos clientes}

A perspectiva do cliente analisa se as ações da empresa aos clientes alvos estão proporcionando os resultados almejados em termos de satisfação, conquista, retenção e lucratividade de clientes, além da participação no mercado (HERRERO FILHO, 2005, p. 30).

Neste ponto, Niven (2005, p. 19) coloca que devem ser respondidas duas perguntas fundamentais: "Qual é nosso público-alvo? Qual é nossa proposta de valor para servi-lo?".

Kaplan e Norton (1997) explicam as perguntas de Niven definindo que as organizações devem identificar os segmentos de clientes e mercados onde desejam atuar. Para obter resultados financeiros é indispensável oferecer valor aos clientes (satisfação do cliente) uma vez que esta perspectiva avalia a situação da empresa em relação à principal fonte de receita da companhia. E, segundo estes autores, a pergunta que se deve fazer é: "Para alcançarmos nossa visão, como deveríamos ser vistos pelos nossos clientes?" (KAPLAN; NORTON, 1997, p. 10).

Uma maneira de oferecer valor para o cliente é aperfeiçoar os processos internos com a finalidade de baixar os custos e tornar a empresa mais competitiva.

Seguindo este viés, é possível perceber que as empresas que não consideram as necessidades de seus clientes acabam por perdê-los para seus concorrentes, visto que o provimento de produtos e serviços alinhados às preferências destes clientes gera um diferencial que os atrai (KAPLAN; NORTON, 1997).

\section{Da perspectiva dos processos internos}

Denota-se relevante o atendimento às expectativas dos acionistas e clientes. No entanto, essa análise deve ser apoiada pelos processos internos críticos, os quais a empresa deve buscar a excelência (Kaplan; Norton, 1997, p. 99).

Ao encontro desta afirmação, a perspectiva dos processos internos busca identificar se os processos centrais da organização definidos em sua cadeia de valor contribuem para o cumprimento das expectativas de seus acionistas, clientes-alvo, e também o atendimento dos objetivos financeiros esperados pela própria organização. Complementa-se que estes processos derivam de estratégias explícitas que objetivam justamente se superar a fim de agregar valor a estes atores, tornando efetivas as suas exigências (KAPLAN; NORTON, 1997; HERRERO FILHO, 2005; NIVEN, 2005).

Em consonância, Kaplan e Norton (1997, p. 10) fazem então, o seguinte questionamento: "para satisfazermos nossos acionistas e clientes, em que processos de negócios devemos alcançar excelência?". A partir deste questionamento, compreende-se que os processos internos condicionam o funcionamento da organização orientada no sentido de satisfazer o cliente, mostrando em quais os pontos a empresa deve se destacar para obter excelência em seu desempenho, e principalmente identificando os processos mais críticos para a realização dos objetivos dos clientes e acionistas.

\section{Da perspectiva de aprendizado e crescimento}

A quarta e última perspectiva do BSC é considerada pilar das três perspectivas anteriores (NIVEN, 2005, p. 20). Ela desenvolve medidas para orientar o aprendizado e crescimento organizacional, oferecendo infraestrutura que possibilita consecução de objetivos ambiciosos das outras três perspectivas, conduzindo-as a excelentes resultados (KAPLAN; NORTON 1997, p. 131).

A Perspectiva de Aprendizado o Crescimento indica qual é o valor do colaborador em face de sua capacidade de aprender, criar e compartilhar conhecimentos e como suas competências contribuem para a geração de valor de forma integrada em todas as perspectivas do BSC (Herrero Filho, 2005, p. 30).

Neste caso, a questão que surge é: "para que se alcance uma visão, como se deve 
Revista de Administração Hospitalar, v.10, n.2, pp. 13-29, maio/agosto, 2013/ Gustavo Vanzo Odebrecht; Pollyanna Gerola Giarola; Jonas Duarte da Silva; Cristina Martins; Carlos Rogério Montenegro de Lima

sustentar a capacidade de mudar e melhorar?" (KAPLAN; NORTON, 1997, p. 10).

Em suma, esta perspectiva identifica a capacidade que a empresa possui para criar processos internos capazes de criar valor para os acionistas e clientes.

\subsection{PLANEJAMENTO ESTRATÉGICO}

Para que se atinja todas as fases, desde a criação até a implantação do BSC, há necessidade de que o planejamento estratégico na organização já tenha sido iniciado, uma vez que a ferramenta se embasa nos pilares das decisões estratégicas, considerados os elementos básicos, conforme cita Niven (2005): a missão, a visão, os valores e os objetivos estratégicos. Segundo Kaplan e Norton (2004, p. 5) a estratégia de uma organização visa criar valor para seus acionistas, clientes e cidadãos, devendo a formulação e a execução da estratégia tratar de forma clara da mobilização e alinhamento dos ativos intangíveis.

Neste contexto, Oliveira (2008, p. 53) percebe a estratégia como "o caminho mais adequado a ser executado para alcançar, preferencialmente de maneira diferenciada, os objetivos, desafios e metas estabelecidos no melhor posicionamento da empresa perante seu ambiente".

Kotler (1993, p. 19) define o planejamento estratégico como o processo de desenvolver e manter um ajuste estratégico entre os objetivos e potencialidades da empresa, e as mudanças de suas oportunidades de mercado.

Assim, subentende-se que para a empresa sobreviver no mercado perante seus concorrentes é necessário a criação de um planejamento estratégico bem estruturado que oriente a melhor direção a ser seguida pela empresa, buscando a otimização do grau de interação com os fatores externos, não controláveis, a fim de atuar de forma inovadora e diferenciada (OLIVEIRA, 2008, p. 17). O planejamento estratégico deve conter: definição da missão, visão e valores da empresa; definição dos objetivos e metas da empresa; planejamento das estratégias.

Kaplan e Norton (1997, p. 2) destacam que o Balanced Scorecard traduz a missão e a estratégia das empresas em medidas de desempenho que subsidiam um sistema de medição e de gestão estratégica.

\section{PROCEDIMENTOS METODOLÓGICOS}

Com a abordagem qualitativa partindo de objetivos exploratórios, se busca descrever a complexidade que envolve um sistema de gestão, principalmente no que tange a área da Saúde, particularmente aqui representada pelo objeto deste estudo, a Clínica de Cirurgia Plástica Jane. Conforme problema levantando na seção 1, pretende-se por meio da análise de fatores encontrados no cenário da organização citada, compreender o seu sistema de decisão a fim de propor a utilização do BSC como ferramenta de apoio a gestão estratégica (RICHARDSON, 1999). Importa considerar que "a variável qualitativa é caracterizada pelos seus atributos e relaciona aspectos não somente mensuráveis, mas também definidos descritivamente" (FACHIN, 2006, p. 81).

Em se tratando da estratégia de pesquisa, utilizou-se a pesquisa bibliográfica juntamente com a análise documental. Estas estratégias utilizam-se de pesquisas anteriormente publicadas e consolidadas no meio científico, incrementadas por documentos institucionais disponibilizados pela Clínica para realização da pesquisa. O que caracteriza a utilização de dados secundários (TRIVIÑOS, 1994).

Ainda em relação à estratégia de pesquisa, enquadra-se como estudo de caso, pois foca no entendimento da dinâmica presente dentro de um único ambiente, no caso representado 
pela Clínica de Cirurgia Plástica Jane.

Neste contexto, cabe aos pesquisadores utilizarem-se ainda do método observacional para examinar e coletar informações consideradas de suma importância para a empresa. Conforme Fachin (2006), o método observacional fundamenta-se em procedimentos de natureza sensorial, como produto do processo em que se empenha o pesquisador no mundo dos fenômenos empíricos. Com isso, para a elaboração do trabalho observaram-se e coletaram-se informações consideradas fundamentais para o desempenho da organização, a fim de estruturar o modelo de ferramenta gerencial de acordo com a sua realidade.

Cabe lembrar que a Clínica Jane é uma Clínica de Cirurgia Plástica localizada em Florianópolis. Entretanto oferece outros serviços como procedimentos de Anestesiologia, Bucomaxilofacial, Ortopedia, Otorrinolaringologia, Oftalmologia, entre outros. Com seis salas de cirurgia, 24 acomodações, possui infraestrutura e instalações modernas que propiciam atendimento 24 horas para urgência/emergências.

Diante disso, este conjunto de método supracitado servirá como alicerce para elaboração do presente artigo.

\section{PROPOSTA DE IMPLEMENTAÇÃO DO BALANCED SCORECARD: CLÍNICA DE CIRURGIA PLÁSTICA JANE}

Apresentam-se nesta seção os resultados da pesquisa. Em outras palavras, a análise do sistema gerencial, observando missão, visão, objetivos estratégicos da organização; a realização da análise SWOT - Strenghts (Forças), Weakness (Fraquezas), Opportunities (Oportunidades) e Threats (Ameaças); bem como a proposta de utilização do BSC para apoio a decisão.

\subsection{CLÍNICA JANE}

A Clínica Jane, localizada em Florianópolis - SC está focada em prestar serviços de saúde, contando com renomados cirurgiões de várias especialidades no seu corpo clínico. Assim sendo, deixa de ser meramente uma clínica de cirurgia plástica e se consolida também como um hospital e maternidade, pois busca atingir especificamente os serviços de Obstetrícia, Maternidade e UTI Neonatal.

A clínica tem como:

- Visão: "Ser a melhor Clínica Cirúrgica do Sul do Brasil."

- Missão: "Fornecer serviços de saúde, priorizando a satisfação dos clientes e profissionais, buscando excelência no atendimento e rentabilidade."

- Valores: "Ética, responsabilidade social e respeito para com o paciente."

Atualmente a empresa é composta por departamentos que são representados no organograma a seguir com suas respectivas funções:

Figura 4 - Organograma da Clínica Jane 


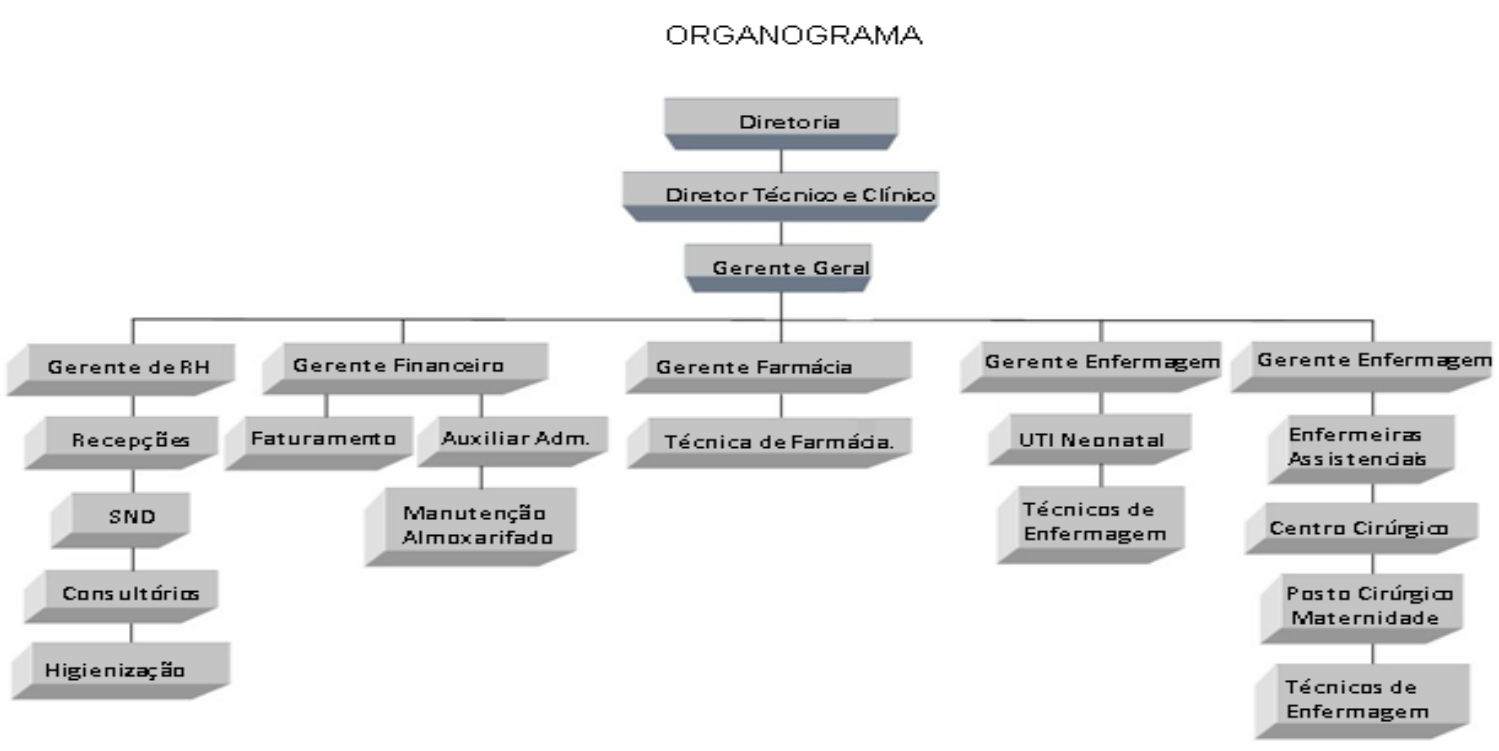

Fonte: documento da Administração, Organograma, (2010).

Pode-se perceber uma ampla gama de profissionais envolvidos na gestão da organização verticalmente organizada. Devido a sua mescla de atividades oferecidas, tornamse complexas as decisões, as quais necessitam cada vez mais de informações bem fundamentadas, principalmente no que tange algumas áreas específicas que tratam diretamente com os clientes ou pacientes que em confiança, depositam à Clínica o seu bem mais precioso, a sua vida.

\subsection{PROPOSTA DE BSC PARA A CLÍNICA JANE}

Esta seção propõe expor os gargalos estratégicos da empresa, uma síntese do planejamento estratégico, a proposta de estruturação do mapa estratégico e do quadro das perspectivas contendo os objetivos estratégicos, medidas (indicadores), metas e iniciativas dentro da metodologia do BSC. Pretende-se, desta forma, auxiliar a direção da Clínica Jane na visibilidade e disseminação do processo de implementação da estratégia organizacional.

\subsubsection{Situação da Empresa}

Confrontando a proposta deste trabalho com a empresa, configura-se os seguintes gargalos de gestão abaixo relacionados:

a) planejamento estratégico não difundido na organização;

b) diretoria sem instrumentos básicos de controle;

c) organograma a ser redimensionando;

d) administração baseada apenas no Caixa;

e) falta de indicadores básicos de controle dos processos;

f) falta de software para o gerenciamento dos processos;

g) inexistência de apuração de resultado econômico gerencial segmentado por mix de serviços;

h) preocupação com qualidade, porém sem aferição;

i) corpo funcional não comprometido com metas básicas;

j) tomada de decisão mais empírica; 
k) não há preocupação com a concorrência;

1) sem controle da qualificação profissional dos colaboradores.

Tendo em vista estas variáveis, acredita-se que o BSC possa contribuir para a estruturação, implantação e implementação dos indicadores base para controle do negócio. $\mathrm{O}$ que motiva discorrer sobre o planejamento estratégico da Clínica.

\subsubsection{Dados do planejamento estratégico}

De acordo com documentos disponibilizados pela administração da clínica, a empresa tem seus fundamentos estratégicos baseados em missão, visão e valores expostos anteriormente. Ressalta-se que apesar de a missão da empresa estar definida, ela não é divulgada entre seus colaboradores; semelhante à missão, a visão recebe atenção muito discreta por parte dos dirigentes e colaboradores da empresa; e os valores são visíveis no dia a dia da organização, quer pela postura da diretoria, como também pelo comprometimento e respeito aos seus clientes e colaboradores.

Visando cumprir sua responsabilidade social, a empresa promove congressos anuais em parceria com a Sociedade Brasileira de Cirurgia Plástica - Regional Santa Catarina, oferecendo para a população local cirurgias plásticas isentas de cobrança de honorários médicos, tornando assim a cirurgia plástica estética e reparadora uma realidade que para muitas pessoas é tida como um sonho.

\subsubsection{Análise $S W O T$}

Com base nos dados recolhidos, apresenta-se a seguir a análise SWOT da Clínica Jane que serve como subsídio para a elaboração da proposta do BSC da Clínica.

\section{Oportunidades:}

Aquisição de Tecnologia de Ponta; Credenciamento de Novos Convênios; Qualificação dos Profissionais; Cirurgias de Baixa Complexidade - Hospital Dia; Cultura à Beleza; Preços; Hotelaria; Localização.

\section{Ameaças:}

Avanços de Tecnologia; Novas Clínicas / Concorrência / Hospitais / Spas; Má remuneração dos Planos de Saúde; Política Econômica do País; Profissionais não Especialistas; Propagandas Enganosas / Locais Inóspitos aos Procedimentos; Falsas soluções em procedimentos.

\section{Pontos Fortes:}

Imagem da empresa; Qualidade no atendimento aos clientes; Credibilidade dos Profissionais; Estrutura Física Confortável; Hotelaria Diferenciada - com caráter familiar; Estacionamento.

\section{Pontos Fracos:}

Comunicação Telefônica; Necessidade de um Programa de Gestão; Necessidade de Programas de Treinamento dos Colaboradores.

\subsubsection{Matriz SWOT}

A partir da análise SWOT e dos documentos acessados da administração, elaborou-se a matriz SWOT da empresa. 
Tabela 1 - matriz SWOT

\begin{tabular}{|c|c|c|c|c|c|c|c|c|c|c|c|c|}
\hline & 12 & 20 & 16 & 28 & 28 & 11 & 6 & 16 & 1 & 17 & INTERNA & \\
\hline \multirow{2}{*}{$\Xi$} & 1 & 1 & 1 & 3 & 3 & 1 & 3 & 1 & 1 & 1 & Aquisição de Tecnologias de Ponta & \multirow{5}{*}{ 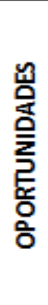 } \\
\hline & 1 & 3 & 3 & 3 & 2 & 1 & 1 & 1 & 1 & 1 & $\begin{array}{l}\text { Credenciamento de Convênios - Planos } \\
\text { de Saúde }\end{array}$ & \\
\hline \multirow{2}{*}{ สี } & 1 & 3 & 1 & 3 & 3 & 3 & 1 & 1 & 3 & 3 & Qualificação dos profissionais & \\
\hline & 1 & 3 & 1 & 3 & 3 & 1 & 1 & 1 & 1 & 1 & $\begin{array}{l}\text { Cirurgias baixa Complexidade - } \\
\text { (Internações em Hospital Dia) }\end{array}$ & \\
\hline$\stackrel{0}{2}$ & 1 & 3 & 1 & 3 & 3 & 1 & 1 & 1 & 1 & 1 & Cultura à beleza & \\
\hline$\cong$ & 1 & 1 & 1 & 3 & 3 & 1 & 3 & 3 & 1 & 3 & Constantes Avanços de Tecnologias & \multirow{5}{*}{ 岕 } \\
\hline ㄴ. & 3 & 3 & 3 & 3 & 3 & 2 & 3 & 3 & 2 & 2 & Aumento da Concorrência & \\
\hline$=$ & 1 & 3 & 3 & 3 & 2 & 1 & 1 & 1 & 1 & 1 & Má Remuneração dos Planos de Saúde & \\
\hline$\Omega^{3}$ & 1 & 2 & 1 & 3 & 3 & 1 & 1 & 3 & 1 & 3 & $\begin{array}{l}\text { Política econômica do País - Baixa do } \\
\text { Poder Aquisitivo }\end{array}$ & \\
\hline$\simeq$ & 1 & 1 & 1 & \begin{tabular}{|l|}
1 \\
\end{tabular} & 3 & 1 & \begin{tabular}{|l|}
1 \\
\end{tabular} & 1 & 1 & 1 & $\begin{array}{l}\text { Propaganda de Profissionais não } \\
\text { Especialistas }\end{array}$ & \\
\hline 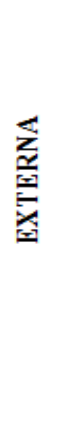 & 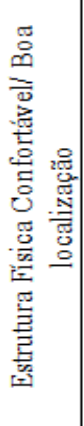 & 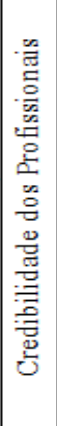 & 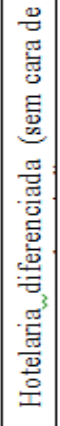 & 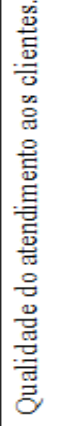 & 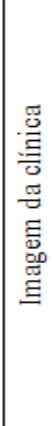 & 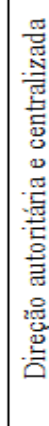 & 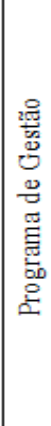 & 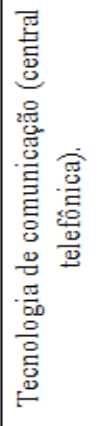 & 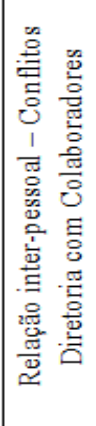 & 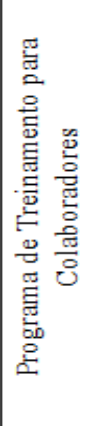 & & \\
\hline & PON & $\mathbf{T}$ & FO & RTE & & & & $\mathbf{R A}$ & & & & \\
\hline
\end{tabular}

Fonte: Elaborado pelos autores a partir de documentos da Administração da Clínica Jane, (2011).

Na Matriz SWOT foram cruzados oportunidade e ameaças com os pontos fortes e fracos, considerando pontuação 1 (um) para "sem relação", 2 (dois) para "relacionado" e 3 (três) para "muito relacionado", totalizando os valores nas respectivas colunas.

A matriz SWOT auxilia a organização na tomada de decisão, com o intuito de maximizar as oportunidades do ambiente em relação aos pontos fortes e minimizar os pontos fracos em relação às ameaças. (Figura 5).

Tendo em vista os pontos de estrangulamentos propõe-se o mapa estratégico do BSC

Figura 5 - Mapa Estratégico Clínica Jane 
Revista de Administração Hospitalar, v.10, n.2, pp. 13-29, maio/agosto, 2013/ Gustavo Vanzo Odebrecht; Pollyanna Gerola Giarola; Jonas Duarte da Silva; Cristina Martins; Carlos Rogério Montenegro de Lima

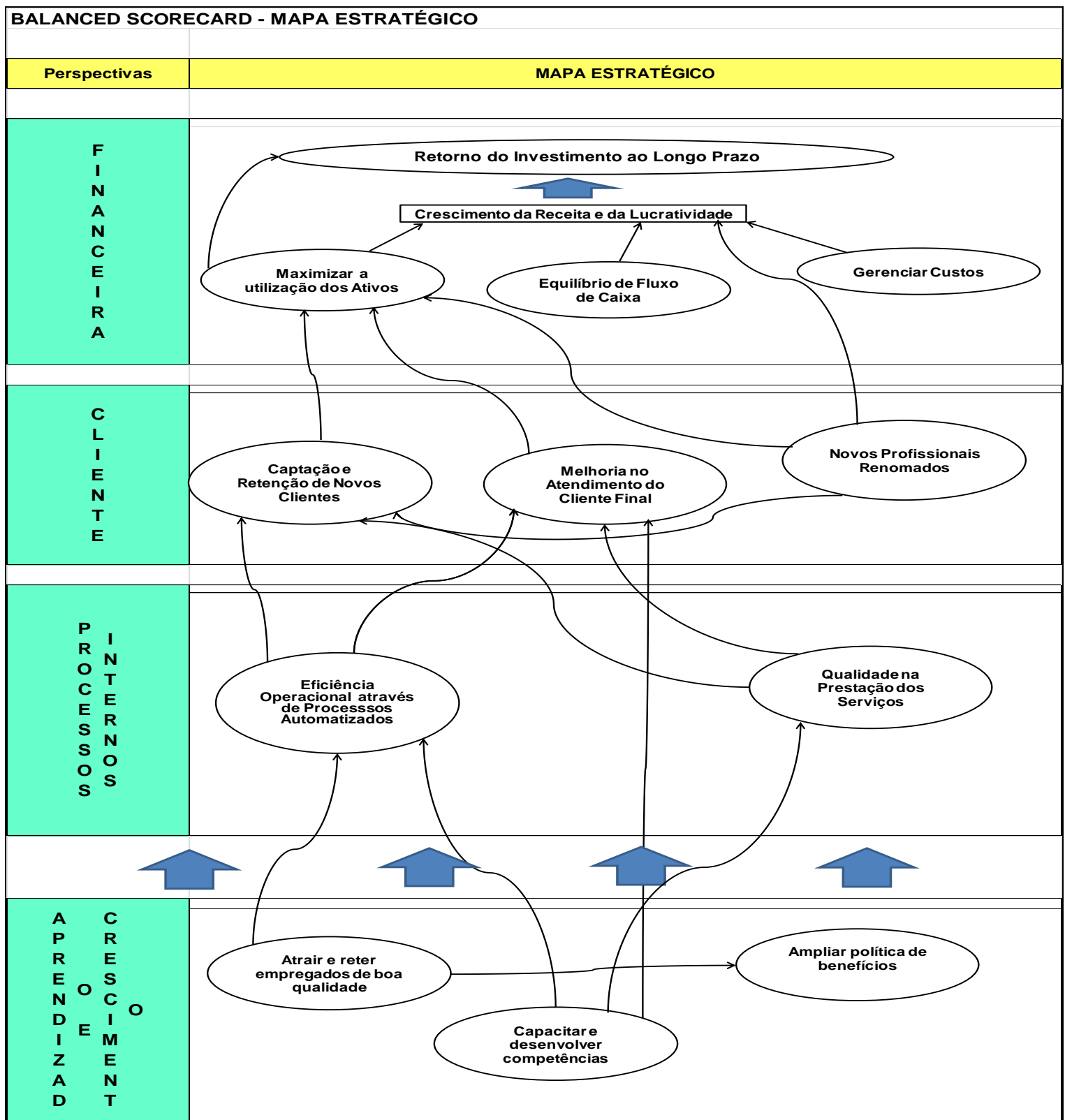

Fonte: Elaborado pelos autores, (2011).

Juntamente com o mapa estratégico proposto para a Clínica, o qual os caminhos objetivam retorno do investimento a longo prazo, apresenta-se o seu respectivo quadro de perspectivas, objetivos, medidas, metas e iniciativas necessárias para que se consiga alcançar o que é almejado pela empresa (vide Quadro 1). 
Revista de Administração Hospitalar, v.10, n.2, pp. 13-29, maio/agosto, 2013/ Gustavo Vanzo Odebrecht; Pollyanna Gerola Giarola; Jonas Duarte da Silva; Cristina Martins; Carlos Rogério Montenegro de Lima

Quadro 1- Perspectivas, objetivos, medidas, metas e iniciativas

\begin{tabular}{|c|c|c|c|c|}
\hline Perspectivas & Objetivos Estratégicos & Medida = Indicador & Metas & Iniciativas \\
\hline \multirow{7}{*}{ Financeira } & \multirow{7}{*}{$\begin{array}{l}\text { Promover um crescimento de } \\
\text { faturamento e lucro sustentável, } \\
\text { promovendo assim o retorno sobre o } \\
\text { investimento, a longo prazo }\end{array}$} & \multirow{4}{*}{ Retorno Sobre o Investimento } & \multirow{4}{*}{$\begin{array}{l}\text { Objetivar um ROI (return on investment) } \\
\text { de } 15 \%\end{array}$} & Maximizar a utilização dos ativos \\
\hline & & & & $\begin{array}{l}\text { Implantar a Cultura da Busca pelo Resultado } \\
\text { Econômico-Financeiro segmentado do negócio; }\end{array}$ \\
\hline & & & & $\begin{array}{l}\text { Estruturar e Apurar o Resultado Econômico- } \\
\text { Financeiro do negócio por Atividade }\end{array}$ \\
\hline & & & & Buscar Equilibrio do Fluxo de Caixa \\
\hline & & \multirow{3}{*}{$\begin{array}{l}\text { Lucratividade / margem líquilda final do } \\
\text { negócio }\end{array}$} & \multirow{3}{*}{ Superar as Margens Médias do Setor } & $\begin{array}{l}\text { Estabelecer política de preços competitivos (com } \\
\text { retorno efetivo); }\end{array}$ \\
\hline & & & & $\begin{array}{l}\text { Estruturar e estabelecer cultura do Resultado } \\
\text { Econômico Financeiro segmentado do negócio por } \\
\text { mix de produtos ou serviços; }\end{array}$ \\
\hline & & & & Gerenciar custos. \\
\hline \multirow{5}{*}{ Clientes } & \multirow{3}{*}{ Melhorar a satisfação dos clientes } & Índice de satisfação dos clientes & 95\% de clientes satisfeitos. & Realizar pesquisa de satisfação; \\
\hline & & \multirow{2}{*}{$\begin{array}{l}\text { Número de médicos especializado e } \\
\text { conceituado }\end{array}$} & \multirow{2}{*}{$\begin{array}{l}\text { Acrescer em } 10 \text { médicos renomados } \\
\text { ao corpo médico }\end{array}$} & Divulgar Imagem da Clínica; \\
\hline & & & & $\begin{array}{l}\text { Promover parceria de investimentos com abertura } \\
\text { da sociedade à profissionais conceituados; }\end{array}$ \\
\hline & \multirow[t]{2}{*}{ Atrair e reter novos clientes } & \multirow[t]{2}{*}{ Quantidade de novos clientes. } & \multirow{2}{*}{$\begin{array}{l}\text { Aumentar em 20\% do número de } \\
\text { clientes da carteira atual }\end{array}$} & $\begin{array}{l}\text { Fazer estudos sobre potenciais novos clientes com } \\
\text { empresa especializada; }\end{array}$ \\
\hline & & & & Introduzir programa de fidelização dos clientes. \\
\hline \multirow{4}{*}{$\begin{array}{l}\text { Processos } \\
\text { Internos }\end{array}$} & \multirow{4}{*}{$\begin{array}{c}\text { Estabelecer Programa de Qualidade na } \\
\text { Clínica }\end{array}$} & \multirow{4}{*}{$\begin{array}{l}\text { Índices de conformidade de um check } \\
\text { list clínico-hospitalar }\end{array}$} & \multirow{4}{*}{$\begin{array}{l}95 \% \text { de conformidade no conjunto de } \\
\text { indicadores estabelecidos; }\end{array}$} & Mapear Processos; \\
\hline & & & & $\begin{array}{l}\text { Introduzir e implementar programas de } 5 S \text { e gestão } \\
\text { de excelência de qualidade }\end{array}$ \\
\hline & & & & Aquisicão de software clínico-hospitalar; \\
\hline & & & & Difundir valores éticos nos negócios \\
\hline \multirow{6}{*}{$\begin{array}{l}\text { Aprendizado et } \\
\text { Crescimento }\end{array}$} & Capacitar e desenvolver competências & $\begin{array}{l}\text { Horas de treinamento e investimento } \\
\text { por pessoa }\end{array}$ & $\begin{array}{l}8 \text { horas de treinamento mensal durante } \\
\text { um ano para os funcionários da } \\
\text { clínicas com desenvolvimento de } \\
\text { competências; }\end{array}$ & $\begin{array}{l}\text { Programas de treinamento para os funcionários da } \\
\text { clinica; }\end{array}$ \\
\hline & \multirow{5}{*}{ Melhorar a satisfação dos funcionários } & Índice de satisfação dos funcionários & $90 \%$ de funcionários satisfeitos; & Pesquisa de clima organizacional \\
\hline & & \multirow{4}{*}{$\begin{array}{l}\text { Gastos com benefícios e programas } \\
\text { sociais }\end{array}$} & \multirow{4}{*}{$\begin{array}{l}\text { Elevar em } 100 \% \text { os gastos com } \\
\text { benefícios aos funcionários; }\end{array}$} & Política de bonificação \\
\hline & & & & Plano de auxílio a farmácia \\
\hline & & & & Distribuição de cestas básicas \\
\hline & & & & Plano de Saúde \\
\hline
\end{tabular}

Fonte: Elaborado pelos autores, (2011).

Buscando uma melhor compreensão do mapa estratégico e do quadro de iniciativas, se faz necessária a interligação entre as perspectivas, como segue.

\section{Perspectiva Financeira:}

$\mathrm{Na}$ perspectiva financeira foi objetivado promover um crescimento de faturamento e lucro sustentável, com o retorno sobre o investimento, a longo prazo. Desta forma, configuram-se como medidas ou indicadores: 1 - o Retorno sobre o Investimento (ROI) e a Lucratividade/Margem Líquida Final do Negócio.

O ROI tem a finalidade de indicar a eficiência do investimento feito na organização. A taxa é calculada pelo Lucro Líquido dividido pelo Investimento, resultando na porcentagem de rentabilidade do período, enquanto o prazo de retorno do investimento é calculado pelo Investimento dividido pelo Lucro Líquido, resultando no tempo real para equilibrar o investimento.

Como meta, se estabeleceu $15 \%$ para o ROI, premissa estipulada a partir da taxa de juros básica mais 6\% de risco para o negócio. Esta taxa mínima de atratividade norteia este tipo de negócio. Para consecução deste objetivo, a empresa precisa de algumas iniciativas:

1 - Maximizar a utilização dos ativos: 
O uso eficiente na locação dos ativos (leitos, salas cirúrgicas e profissionais), ou seja, procedimentos sincronizados dos processos;

2 - Buscar o equilíbrio do fluxo de caixa operacional:

Este aspecto está atrelado fortemente à capacidade de liquidez do negócio. Portanto mensurar a necessária capacidade de capital de giro, em outras palavras, é ter sob controle o saldo de caixa operacional, pois muitas vezes a utilização inadequada deste capital de giro na imobilização traz problemas de liquidez.

3 - Gerenciar custos:

No mundo dos negócios tem-se uma certeza: podemos controlar custos a partir de procedimentos básicos de gestão e informação;

4 - Criar cultura do resultado do negócio por segmentação:

Estruturar um sistema de informações para apoio à decisão com foco no resultado por segmentação, como, por exemplo, partir do segmento de Plástica Embelezadora, Plástica Corretiva, Cirurgias Curativas, dentre outras aberturas.

5 - Estabelecer política de preços competitivos

Buscar informações de custos confiáveis para formação do preço no intuito de promover política de preços que promova retorno efetivo e seja instrumento de negociação para com os clientes.

\section{Perspectiva do Cliente:}

Para se atingir a visão, na perspectiva do cliente, foram propostas os seguintes objetivos: melhorar do satisfação do cliente e captar e reter novos clientes.

Para realização destes objetivos estratégicos foram propostas duas medidas e metas:

a) Quanto a proposta de melhorar a satisfação do cliente:

Índice de satisfação dos clientes; Obter noventa e cinco por cento da satisfação de clientes. Número arrojado, porém necessário no alcance da melhoria contínua dos processos. Esta meta pode ser estimativa através de Pesquisas de Satisfação do Cliente.

b) Número de médicos especializado e conceituado:

Outra meta é aumentar o corpo clínico com clientes fidelizados. A fidelização de clientes na clínica é um ponto difícil de ser alcançado, pois estes se vinculam sempre ao profissional médico - a alternativa é fidelizar o médico à clínica, pois este trará seus pacientes para seus respectivos procedimentos, divulgando a imagem da Clínica Jane.

Quanto ao objetivo estratégico de atrair e reter novos clientes, a medida está baseada obviamente pela adesão de novos clientes aos serviços da clínica. Porém o patamar pretendido ou a meta é de acrescentar em $20 \%$ a carteira atual de clientes. Tal meta está alicerçada em duas iniciativas, a saber: $1^{\text {a }}$ - Fazer estudos sobre potenciais novos clientes com empresa especializada; $2^{\mathrm{a}}$ - Introduzir programa de fidelização dos clientes.

\section{Perspectiva dos Processos Internos:}

Nos processos internos, o objetivo é estabelecer um Programa de Qualidade na Clínica onde se busca a qualidade nos serviços prestados. Este objetivo passa pela vinculação do corpo de colaboradores - um sistema de qualidade voltado às informações básicas de controle clínico/hospitalar. As iniciativas para a realização destas medidas consistem em mapear os processos, introduzir e implementar programas de $5 \mathrm{~S}$ e gestão de excelência da qualidade e inclusive difundir valores éticos nos negócios. Assim, a consecução deste objetivo estratégico requer outra iniciativa no âmbito dos investimentos que é a aquisição de software clínicohospitalar.

\section{Perspectiva de Aprendizagem e Crescimento:}

Nesta perspectiva foram fixados dois objetivos: $1^{\circ}$ - Capacitar e desenvolver 
competências; $2^{\circ}$ - Melhorar a satisfação dos funcionários. Para tanto são propostas seis medidas a saber;

Quanto ao primeiro objetivo - capacitar e desenvolver competências, tem-se uma iniciativa estratégica atrelada: $1^{\mathrm{a}}$ - Programas de treinamento para os funcionários da clínica. Está iniciativa tem como meta oito horas de treinamento mensal por funcionário durante um ano a fim de desenvolver e aprimorar o desenvolvimento de competências;

Para o segundo objetivo - melhorar a satisfação dos funcionários, propõe-se cincos iniciativas; $1^{\mathrm{a}}$ - Pesquisa de clima organizacional; $2^{\mathrm{a}}$ - Política de bonificação; $3^{\mathrm{a}}$ - Plano de auxílio a farmácia; $4^{\mathrm{a}}$ - Distribuição de cestas básicas; $5^{\mathrm{a}}$ - Plano de Saúde. Ressalta-se que tais iniciativas são amplamente desenvolvidas nas empresas do setor privado, ou seja, tornamse importantes para atrair e reter funcionários e manter um patamar adequado de satisfação dos mesmos.

\section{CONSIDERAÇÕES FINAIS}

O Balanced Scorecard foi considerado uma das 75 melhores e mais influenciadoras ideias de negócio do século XX pela Harvard Business Review. A metodologia foi adotada por mais de 500 empresas entre as 1000 maiores da Fortune sendo então, amplamente utilizada, corroborando com diversos casos bem-sucedido em nível mundial (NIVEN, 2008).

Tal destaque se deve pela capacidade da ferramenta BSC oferecer uma ligação fundamental para transformação da estratégia em ação em todos os níveis da empresa e definir todos os bens intangíveis como, por exemplo, capital intelectual, relacionamentos com os clientes e inovações em verdadeiro valor.

Este artigo teve por objetivo propor a estruturação de um BSC como ferramenta de gestão estratégica organizacional para a Clínica de Cirurgia Plástica Jane de Florianópolis, de forma a contribuir para que a organização possa, além de monitorar resultados financeiros, acompanhar o progresso na construção da aquisição de ativos intangíveis necessários para o crescimento futuro.

Para isso, foram identificados os objetivos estratégicos da empresa; realizada a análise SWOT - Strenghts (Forças), Weakness (Fraquezas), Opportunities (Oportunidades) e Threats (Ameaças); elaborado o mapa estratégico na metodologia do BSC o que permite uma visão holística e alinhada das estratégias desdobrando-as até seu nível funcional; e propostos indicadores, metas e iniciativas para os objetivos organizacionais dentro das perspectivas do BSC.

Conclui-se que a utilização do Balanced Scorecard como ferramenta de gestão estratégica possibilita haver um claro entendimento de como as decisões dos gestores da Clínica Jane podem impactar diretamente não apenas na sua área de responsabilidade, mas também em toda a estratégia da empresa, auxiliando na relação das ações atuais com as metas de longo prazo e promovendo a sinergia da empresa para atingir os objetivos em observância à missão estabelecida.

\section{REFERÊNCIAS}

BASSO, L. F. C.; PACE, E. S. U. Uma análise crítica da direção da causalidade no Balanced Scorecard. RAE Eletrônica. v. 2, n. 1, jan./-jun. 2003. Disponível em: <http://rae.fgv.br/sites/rae.fgv.br/files/artigos/10.1590_S1676-56482003000100012.pdf>. Acesso em: 7 jan. 2012. 
Revista de Administração Hospitalar, v.10, n.2, pp. 13-29, maio/agosto, 2013/ Gustavo Vanzo Odebrecht; Pollyanna Gerola Giarola; Jonas Duarte da Silva; Cristina Martins; Carlos Rogério Montenegro de Lima

CLÍNICA JANE. Dados da empresa. Disponível em: <www.clinicajane.com.br〉. Acesso em: 20 dez. 2011.

COELHO, Márcio. A essência da administração: os conceitos introdutórios. São Paulo: Saraiva, 2008.

FACHIN, O. Fundamentos de metodologia. 5. ed. São Paulo: Saraiva, 2006.

GIL, A. C. Métodos e técnicas de pesquisa social. 6. ed. São Paulo: Atlas, 2008.

HERRERO FILHO, E. Balanced scorecard e a gestão estratégica. Rio de Janeiro: Elsevier, 2005.

KAPLAN, R.; NORTON, D. P. A estratégia em ação: Balanced Scorecard. 8 ed. Rio de Janeiro: Campus, 1997.

KAPLAN, R. S.; NORTON, D. P. Kaplan e Norton na prática. Rio de Janeiro: Elsevier, 2004.

KIM, W. C. A estratégia do oceano azul: como criar novos mercados e tornar a concorrência irrelevante. Rio de Janeiro: Elsevier, 2005.

KOTLER, P.; AMSTRONG, G. Princípios de marketing. Rio de Janeiro: Prentice-Hall do Brasil, 1993.

LIMA, C. R. M.; SOARES, T. C.; LIMA, M. A. Balanced Scorecard em instituições de ensino superior: uma análise das perspectivas. Revista Eletrônica de Estratégia e Negócios, Florianópolis, v. 4, n. 1, p. 183-205, jan./jun. 2011.

LUZ, M. S. Implantação e benefícios da utilização do Balanced Scorecard na administração pública: o caso do Superior Tribunal de Justiça. 2010. 89 f. Monografia (Graduação em Administração) - Universidade de Brasília - Unb, Brasília, 2010.

NIVEN, P. R. Balanced Scorecard passo-a-passo: elevando o desempenho e mantendo os resultados. Rio de Janeiro: Qualitymark, 2005.

OLIVEIRA, D. de Pinho de. Planejamento estratégico: conceitos metodologia prática. 25 ed. São Paulo: Atlas, 2008.

RICHARDSON, R. J. Pesquisa social: métodos e técnicas. 3. ed. São Paulo: Atlas, 1999.

SERRA, F.; TORRES, M. C. S.; TORRES, A. P. Administração estratégica: conceitos, roteiro prático e casos. Rio de Janeiro: Reichmann \& Affonso Editores, 2003.

TRIVIÑOS, A. N. S. Introdução à pesquisa em ciências sociais: a pesquisa qualitativa em educação. São Paulo: Atlas, 1994. 